\title{
Qualitative Studies of "Bacouri”: A Greek High Quality Vine Variety
}

\author{
Pantelis Zamanidis \\ National Agricultural Research Foundation \\ Sofokli Venizelou 1, 14123, Lykovrissi, Greece \\ Tel: 30-210-284-5940 \\ Nicholas E. Korres (Corresponding author) \\ Environmental Research Institute \\ University College Cork, Lee Road, Cork, Ireland \\ E-mail: nkorres@yahoo.co.uk \\ Dimitris Argyropoulos \\ National Agricultural Research Foundation \\ Sofokli Venizelou 1, 14123, Lykovrissi, Greece \\ Tel: 30-210-284-5940
}

Received: September 21, $2010 \quad$ Accepted: October 15, 2010 doi:10.5539/jas.v3n2p56

\begin{abstract}
The morphological description of the vine variety Bacouri (Vitis Vinifera L. spp. sativa) that is based on descriptors defined by the Organization Internationale de la Vigne et du Vin (OIV) is presented in this paper. The variety Bacouri was investigated as being a valuable Greek variety for the production of high-quality red wines of different classes. Morphological characteristics, technological features with recommendations for red wine production using micro wine-making methods and the economic importance of the variety are provided. Its value in vine breeding has also been taken under consideration. The origin of the variety is the Peloponnese region, in the south part of Greece and it is a descendant of the region's wild species of Vitis sylvestris.
\end{abstract}

Keywords: Bacouri, Vitis vinifera, Morphology, (OIV), Vine variety

\section{Introduction}

The Vitaceae (Lindl) Juss family consists of at least 16 genera of which the genus Vitis (Tournef) L. is the most important. It includes 70 Vitis species and more than 40.000 varieties grouped into two sub-genera, the Euvitis Planch $(2 \mathrm{n}=38)$ and Muscadinia Planch $(2 \mathrm{n}=40)$. According to the existing data, varieties of Vitis (Tournef) L. are found in most continents although for many reasons, along with economical reasons, there is not yet a complete collection in a common genetic bank. The banks of genetic material around the world for Vitis differ, consisting mostly of local Vitis genotypes. The largest Vitis collections are found in France, USA, India and Ucraine. (Alleweldt and Blaich, 1988; Alleweldt and Dettweiler, 1994; Galet, 1998).

Greece is one of the oldest areas of genesis and formation of cultivated grapevine. The ancient culture in favorable natural situations, as also the long process of natural and artificial selection resulted in a great diversity of cultivated Vitis varieties that survived up to nowadays. The Vitis collection of the Institute of Viticulture at Likovrisi in Athens (Greece), one of the largest in the Balkan region, includes more than 800 Vitis varieties from all over Greece. The most of them (98\%) are Vitis vinifera, while $60 \%$ of them are local varieties. Information for Greek vine varieties and their potential in breeding currently is scarce. The aim of this work, as part of a wider effort for the taxonomy and evolution of Greek vines, was to characterize the promising variety Bacouri, based on common methods, for future vine breeding and the development of new varieties. In terms of morphological parameters, the variety Bacouri is close to the wild vine Vitis vinifera L. ssp. silvestteris Gmel. In terms of its morphological-physiological parameters the variety belongs to the ecological-geographical group of 
varieties Vitis vinifera spp. sativa D. C. convar pontica Negr. subconvar balcanica Negr. (Negrul, 1938; Negrul, 1946; Krimbas, 1943). The variety Bacouri was investigated as being a valuable Greek variety for making high-quality wines for different classes and for its use in breeding new vine varieties with unique characteristics.

\section{Materials and methods}

\subsection{Environmental characteristics of the study region}

The Vitis collection of the Institute of Viticulture in Athens, is located at the North East part of Athens $\left(37^{\circ} 58^{\prime}\right.$ $\mathrm{N}$ and $\left.23^{\circ} 24^{\prime} \mathrm{E}\right), 210 \mathrm{~m}$ above the sea level. The climate is Mediterranean with hot dry summers and mild winters. The absolute maximum temperature, at shade, is $+45{ }^{\circ} \mathrm{C}(2007)$ hence the critical for the grapevine temperatures $\left(+40{ }^{\circ} \mathrm{C}\right)$ are reached every year in this area. The annual level of precipitation is around $360-600 \mathrm{~mm}$ and occurs mainly during winter period. The soil contains $1 \%$ organic matter, whereas $\mathrm{CaCO}_{3}$ concentration ranges between $12 \%-15 \%$ of the total dry mass. $\mathrm{pH}$ values range between 7.6-8.1.

\subsection{Background information}

The study of the Greek Vitis vinifera red variety with common name Bacouri, was performed in vine plants grafted on Richter-110 (R-110), a Vitis hybrid, reputed as drought-tolerant. Plants used in this study were 12 years old and $60 \mathrm{~cm}$ height. Applications in breeding experiments need macroscopic descriptors as basis for selection. Additionally, newer technologies based on genetic descriptors, as a valuable taxonomic tool, can be enhanced to their full potential when related to macroscopic evidences (This et al., 2006; Lefort and Roubelakis-Angelakis, 1999). The morphological description of the variety Bacouri and subsequent parameters coding were conducted based on the recommended methodology of the Organization Internationale de la Vigne et du Vin - OIV (2001).

\subsection{Vine crop establishment}

Grafted vines were planted in lines with $2 \mathrm{~m}$ distance between lines and every year were shortened to 2 buds per branch, leaving in total 16 to 18 buds for clematis formation. All basic cultivation procedures (e.g. fertilization and plant protection) were based on common husbandry practices and were performed regularly every year maintaining standard growth conditions.

\subsection{Study of the variety}

The study of the variety was conducted based on the following procedures.

\subsubsection{Determination of the name}

The determination of the variety's name was based on previous studies regarding the most commonly cultivated areas, the origin of the variety and its geographical distribution (Viala and Vermorel, 1901; Krimbas, 1943).

\subsubsection{Botanical description}

The botanical description of the variety was performed based on morphological characteristics of certain parts of the plant such as the young clematis, one year old clematis, leaf shape, flower, grape and seed. The morphological futures were evaluated and expressed according to the categorical numbering based on the definitions provided by O.I.V. (2001).

\subsubsection{Physiological studies}

The physiological studies of the variety were considered aspects of: Phenological observations, the production period from the time of bud formation to the collection of grapes, the quality and quantity of produced grapes, the woody formation of one year shootings, the successful grafting with rootstock Vitis species, the cold and draught tolerance, the disease resistance, the tolerance in active calcium, the self pollination ability and the adaptation in different environments (Pearson and Goheen, 1988)

\subsubsection{Biochemical properties}

The biochemical properties of the grapes, red wine production including the starting period for grape harvesting, sugar content, acidity and fermentation parameters (temperature, carbohydrates, alcohol) were also studied according to methods proposed by Egan et al. (1981).

\subsubsection{Breeding potential}

Clone production and inheritance of the basic characteristics was based on studies with sporophytes from breeding experiments that has been previously described (Zamanidis, 2006), using cross pollination with other Vitis varieties, collection of hybrid grape seeds, planting of the seeds and cultivation of hybrid plants, study of the hybrid plants, selection of the best hybrid plans and breeding. 


\section{Results and Discussion}

The origin of the variety is from the region of Peloponnese. It is cultivated in the areas of Korinthia, Arcadia, Argolida and Achaia. According to EU law, the variety Bacouri is not yet included in the catalogue of grape varieties (FEC 684B/1992) and it is not a declared region variety.

The following data provide information for the morphological description according to the guidance of OIV (2001).

\subsection{Young shoot}

Description of the young shoot (Figure 1a-front and Figure 1b-back side respectively) according to OIV (2001) is listed below.

001 - Form of tip (crown) of the young shoot: 7 - opened;

002 - Distribution of the anthocyanin coloration of tip: 3 -overall;

003 - Intensity of the anthocyanin coloration of tip: 5 -medium;

004 - Density of the prostrate hairs of tip: 9 -very dense;

005 - Density of the erect hair of tip: 1 - none or very sparse;

006 - Attitude: 3 -semi-erect;

007 - Color of the dorsal side of the internode: 2 - green with red stripes;

008 - Color of the ventral side of the internodes: 2 - green with red stripes;

009 - Coloring of the dorsal side of nodes: 3 - red;

010 - Color of ventral side of nodes: 1 -green;

011 - Density of erect hairs of the nodes:1-none or very sparse;

012 - Density of erect hairs on internodes:1-none or very sparse;

013 - Density of prostrate hairs on the nodes: 3 -sparse;

014 - Density of prostrate hairs on the internodes: 1-none or very sparse;

015 - Anthocyanin coloration of the buds: 3 - weak;

016 - Tendrils. distribution on the shoot: 1 -discontinuous;

017 - Length of the tendrils: 7 - long.

\subsection{Young leaf}

Description of a young leaf (Figure 1a - front and Figure 1b - back side respectively) following the coding system based on OIV (2001) is as follow.

05 1- Color of the upper side: 2- green with bronze spots;

052 - Intensity of the anthocyanin coloration of 6 distal leaves: 5 - medium;

053 - Density of prostrate hairs between veins: 7 -dense;

054 - Density of erect hairs between veins: 1 - none or very sparse;

055 - Density of prostrate hairs on main veins: 9 -very dense;

056 - Density of erect hairs on main veins:1-none or very sparse.

\subsection{Mature leaf}

The characteristics of the mature leaf of Bacouri variety (Figure 2a-front and Figure 2b-back side respectively) according to OIV (2001) can be coded as follow:

065 - Size: 5 - medium;

066 - Length: 3 - short;

067 - Shape of blade: 3 - pentagonal;

068 - Number of lobes: 4 - seven;

069 - Color of the upper side of blade: 7 -dark green;

070 - Anthocyanin coloration of the main nerves of the upper side of the blade: 1 - absent or very weak; 
071 - Anthocyanin coloration of the main veins on the lower side of the blade : 3 - weak;

072 - Goffering of blade: 1 - absent;

073 - Undulation of blade between main and lateral veins: 3 - overall;

074 - Profile: 5 - rolled;

075 - Blistering of upper side: 5 - medium;

076 - Shape of teeth: 2 - both sides rectilinear;

077 - Length of teeth: 7 - long;

078 - Length of teeth compared with their width at the end of the base: 7 - long;

079 - General shape of petiole sinus : 7 - lobes overlapping;

080 - Shape of base of petiole sinus: 2 - V shaped;

081 - Peculiarities of petiole sinus: 1 - none;

082 - Shape of upper leaf sinuses: 3 - lobes slightly overlapping;

083 - Shape of base of upper leaf sinuses: 2 - V shaped;

084 - Density of prostrate hairs between the veins: 5 - medium;

085 - Density of erect hairs between the veins: 1 - none or very weak;

086 - Density of prostrate hairs on main veins: 5 - medium;

087 - Density of erect hairs on main veins: 1 - none or very weak;

088 - Prostrate hairs on main veins: 9 - present;

089 - Erect hairs on main veins: 1 - absent ;

090 - Density of prostrate hairs on petiole: 1 - none or very sparse;

091 - Density of erect hairs on petiole: 1 - none or very sparse;

092 - Length of the petiole: 3 - short;

093 - Length of the petiole compared to middle vein: 5 - equal.

\subsection{Woody shoot}

The same coding procedure (OIV, 2001) for the description of the woody shoot was followed:

101 - Cross-section : 2 - elliptic;

102 - Surface: 1 - smooth;

103 - Main color : 4 - reddish-brown;

104 - Lenticels: 1-absent;

105 - Density of erect hairs of nodes: 1- none or very weak

106 - Density of erect hairs of internodes: 1- none or very weak

\subsection{Inflorescence}

Inflorescence of Bacouri can be described as follows:

151 - Sex of flower: 3 - hermaphrodite;

152 - Insertion of the $1^{\text {st }}$ inflorescence: 2 - at 3 rd or 4 th node;

153 - Number of inflorescences per shoot: 2 - from 1.1 to 2 inflorescence;

154 - Length of proximal inflorescence : 5 - medium.

\subsection{Bunch and berry (Fig. 3)}

The bunch (Figure 3a), berry (Figure 3b) and seed (Figure 3c) of the Bacouri variety based on OIV Code (2001) are described as follows:

201 - Number of bunches per shoot: $2-1.1$ to 2 bunches;

202 - Size of the bunch (length + width): 5- medium;

203 - Length of the bunch: 5 - medium; 
204 - Density of the bunch: 7 -dense;

205 - Number of berries per bunch: 5 - medium;

206 - Length of the stem of the bunch: 5- medium;

207 - Lignification of peduncle: 3 - weak;

220 - Size of the berry: 5 - medium;

221 - Length of the berry: 5-medium;

222 - Uniformity of size: 2 -uniform;

223 - Shape of the berry: 3-roundish;

224 - Cross-section of the berry: 2- circular;

225 - Color of skin: 6 - blue-black;

226 - Uniformity of color of skin: 2 -uniform;

227 - Waxy coating (thickness of the berry cuticle): 5 - medium;

228 - Thickness of the berry skin: 5 - medium;

229 - Hilum of berry: 2 - visible;

230 - Coloring of the berry flesh: 1 -not colored;

231 - Intensity of the color of the berry flesh: 1 - not colored or very slightly colored;

232 - Juiciness of the berry flesh: 2 - juicy;

234 - Firmness of the berry flesh: 1 - soft;

236 - Particular flavor: 4 - other;

237 - Classification of flavor: 2 - little flavor;

238 - Length of the berry pedicel; 5 - medium;

239 - Berry separation from pendicel: 1 - difficult;

241 - Presence of seeds in the berry: 3 - present;

242 - Length of the seed: 5 - medium;

243 - Weight of the seed: 5-medium;

244 - Transversal ridges on dorsal side of seed: 1 - absent.

3.7 Buds and canes (Fig. 4)

Canes (Figure 4a) and buds (Figure 4b) of Bacouri variety according to OIV (2001) can be coded as follows:

301 - Time of bud burst: 5 - medium

302 - Time of full bloom; 5- medium

303 - Begin of the berry ripening: 5 - medium;

304 - Physiological stage of full maturity of the berry: 5 - medium;

305 - Begin of wood maturity: 3 - early;

306 - Autumn coloring of leaves: 2 - reddish;

351 - Vigor of shoot growth: 5 - medium;

352 - Growth of axillary shoots: 3-weak

353 - Length of internodes: 5 - medium;

354 - Diameter of internodes: 5 - medium.

3.8 Resistance and must production

401 - Resistance to iron chlorosis: 7-high;

402 - Resistance to chlorides (salt); 7 - high;

403 - Resistance to drought: 7 - high; 
452 - Degree of resistance to Plasmopara (leaf) : 5 - medium;

456 - Degree of resistance to Oidium (cluster): 5 - medium;

459 - Degree of resistance to Botrytis (cluster): 5 - medium;

503 - Single berry weight: 5 - medium;

504 - Bunch weight / ha: 9 - very high;

505 - Sugar content of must \% w/v: 9- very high;

506 - Total acid content of must g/l: 3 - low;

The duration of the productive period (from the beginning of the bud opening to the harvesting of the yield) is 136-145 days. The variety exhibits medium growth since the length of the shootings lies between 1.3-2.0 m. The degree of ripening of the shootings is high between $81-95 \%$. The yield can reach $17 \mathrm{t} / \mathrm{ha}$ or even higher. However, the production of high-quality wine requires the regulation of the number of bunches per grapevine. When the amount of grapes of the grapevines is $3-4 \mathrm{~kg}$, then high-quality red wine is produced. The percentage of fructiferous shoots is $90 \%$, and the number of bunches per shoot is $1-2$. The weight of the separate bunches of grapes is at least $600 \mathrm{~g}$ whereas the variety grows well on poor, dry and limy soils.

The variety is strongly resistant to drought but responds well to fertilization and irrigation resulting in increased yields, It is relatively resistant to cold, with medium resistance to mildew (Erysiphe graminis), downy mildew (Peronospora spp.) and botrytis (Botrytis cinerea) and good compatibility to the regional rootstocks.

The stem-cup shape of the trees is done with the trunk length $40-60 \mathrm{~cm}$, at planting scheme 1.2-1.5 or 2.0-2.5 m and with 3-5 branches in order to maintain stable and high-quality yield. The cutting is done at 2 buds at loading of the vines with 12-15 fruiting shoots. The variety is also cultivated as cordon royal with trunk height 110-120 $\mathrm{cm}$ at planting scheme 1.2-1.5 x 2.0-3.0 m. The pruning is done at 2 buds too, and the loading is increased to $15-18$ or $16-20$ fructiferous canes.

\subsection{Phenology observations}

In the Attica region the burst of the buds begins during the first ten days of April, the blooming starts at the end of May and the beginning of the ripening the first ten days of August and is completed at the last ten days of August. The average weight of bunch is $400 \mathrm{~g}$, the average weight of 100 berries is $390 \mathrm{~g}$ and the average weight of 100 seeds is $3.2 \mathrm{~g}$. As a percentage of the total weight of the bunch the grapes are $94 \%$, and of the stem $6 \%$. As a percentage of the total weight of the berries, the juice and the flesh are $89 \%$, and the skin and seeds $11 \%$. The sugar concentration in the juice of the berries is over $23 \mathrm{~g} / 100 \mathrm{~cm}^{3}$ and the titrate acidity is $5-6 \mathrm{~g} / \mathrm{l}$.

\subsection{Technology applications}

The micro wine making method produced a unique red wine with the following parameters: alcohol content: $13.0-14.0 \%$ vol., titrate acidity $4.6-5.7 \mathrm{~g} / 1$ while fructose content varied between $1-2 \mathrm{~g} / 100 \mathrm{~cm}^{3}$. The wine was red-purple color, with good body, light in tannins and rich in phenols which allows it to be consumed as a young wine, with a complex aroma of forest fruit and spices. The variety is very promising for cultivation in all regions for making high-quality wines. It can be used for genetic improvement of existing grape varieties and as a source of genes of valuable biological-economical significance being equally important as other popular varieties (Pino Noir, Merlot, Sirach and Cabernet-Sauvignon).

\section{Conclusion}

Studies with macroscopic descriptors of the variety Bacouri, provide basic valuable information of genetic material for the production of new quality wines. Bacouri vine variety due to its remarkable characteristics, as it is described above, along with its high quality wine production, its tolerance in drought and various common vine diseases offers new potential for wine products with new tastes and flavors. In addition it can serve as a donor for genetic material for new hybrid vine varieties with unique viticultural and oenological characteristics.

\section{References}

Alleweldt, G., \& Blaich, R. (1988). The genetic resources of Vitis. World list of grapevine collections, 120. Siebeldingen, FRG.

Alleweldt, G., \& Dettweiler E (1994). The Genetic Resources of Vitis: World List of Grapevine Collections. (2nd edn), Geilweilerhof.

Galet, P. (1998). Grape Varieties and Rootstock Varieties. Oenoplurimedia. Chaintre, France.

Krimbas, V. (1943). Greek Ampelography, Vol. 1. Athens, Greece: Greek Ministry of Agriculture. 
Lefort, F., \& Roubelakis-Angelakis, K. A. (1999). Genetic comparison of Greek cultivars of Vitis vinifera L. by nuclear microsatellites profiling, Am. J. Enol. Vitic, 52, 101-108

Negrul, A. M. (1938). Evolution of cultivated forms of grapes. CR Acad Sci USSR, 18, 585-588

Negrul, A. M. (1946). Origin and classification of cultured grape. In The Ampelography of the USSR, Vol. 1 (ed. A. Baranov, Y. F. Kai, M. A. Lazarevski, A. M. Negrul, T. V. Palibin \& N. N. Prosmoserdov) Moscow: Pischepromizdat, pp 159-216.

Office International de la Vigne et du Vin. (2001). Code descaracte 'res descriptifs des varie' te' s et espe 'ces de Vitis. OIV, Paris.

Egan, H., Kirk, R. S., \& Sawyer R. (1981). Pearson's Chemical Analysis of Foods. Churchill Livingstone.

Pearson, R. C. \& Goheen, A. C. (1988). Compendium of Grape Diseases, ed. APS Press, American Phytopathological Society.

This, P., Lacombe1, T., \& Thomas, M. R. (2006). Historical origins and genetic diversity of wine grapes. Trends in Genetics, 22(9), 511-519.

Viala, P., \& Vermorel, V. (1901-09). Ampelographie. Traité général de viticulture Vol. 1-7, Maison.

Zamanidis, P. (2006). Genetic Improvement of Greek wine producing grape varieties at the wine institute of Athens. Ampelos 2006, Proceedings of the 2nd International Symposium on the evaluation and exploitation of the grapes of corresponding terroir through winemaking and commercialization of wines.

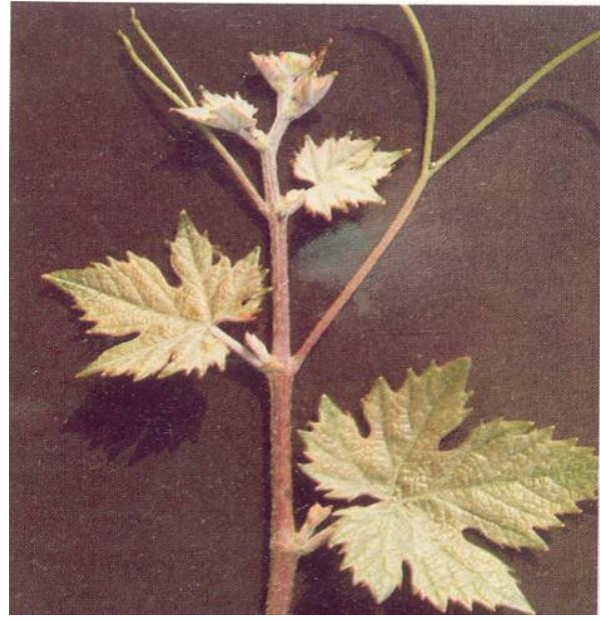

a

Figure 1. Tip of a young shooting of the vine variety Bacouri (a) upper (b) back side

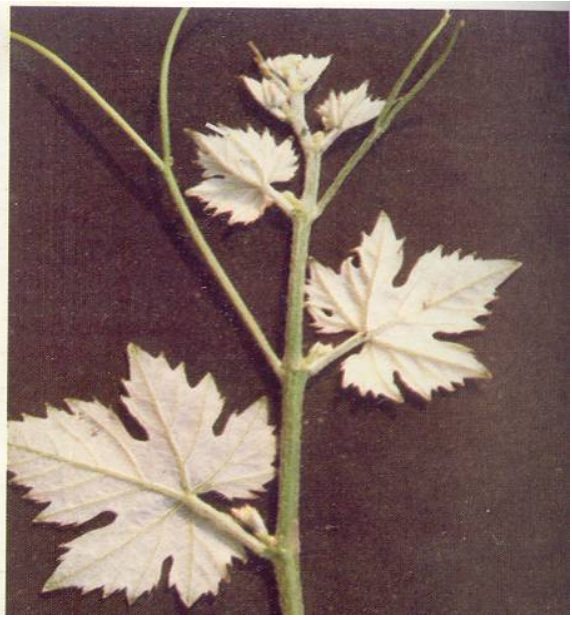

b



a

b

Figure 2. Mature leaf of the vine variety Bacouri (a) upper (b) back side 


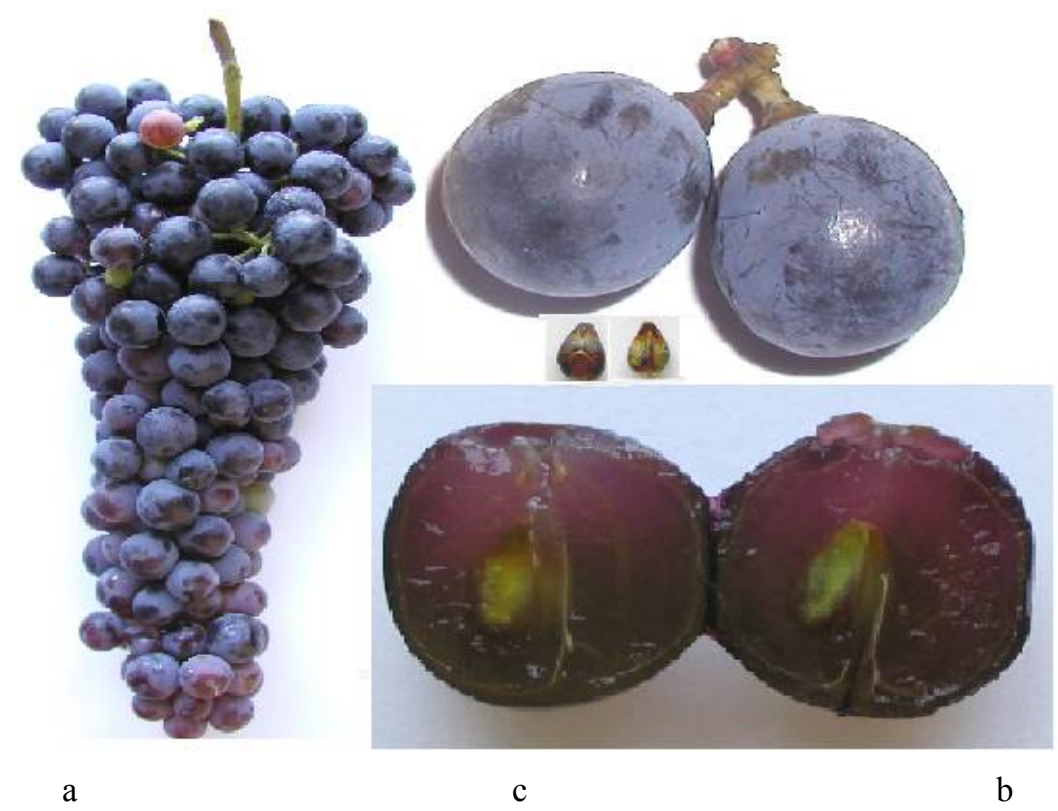

Figure 3. (a) Bunch, (b) berries and (c) seeds of the vine variety Bacouri

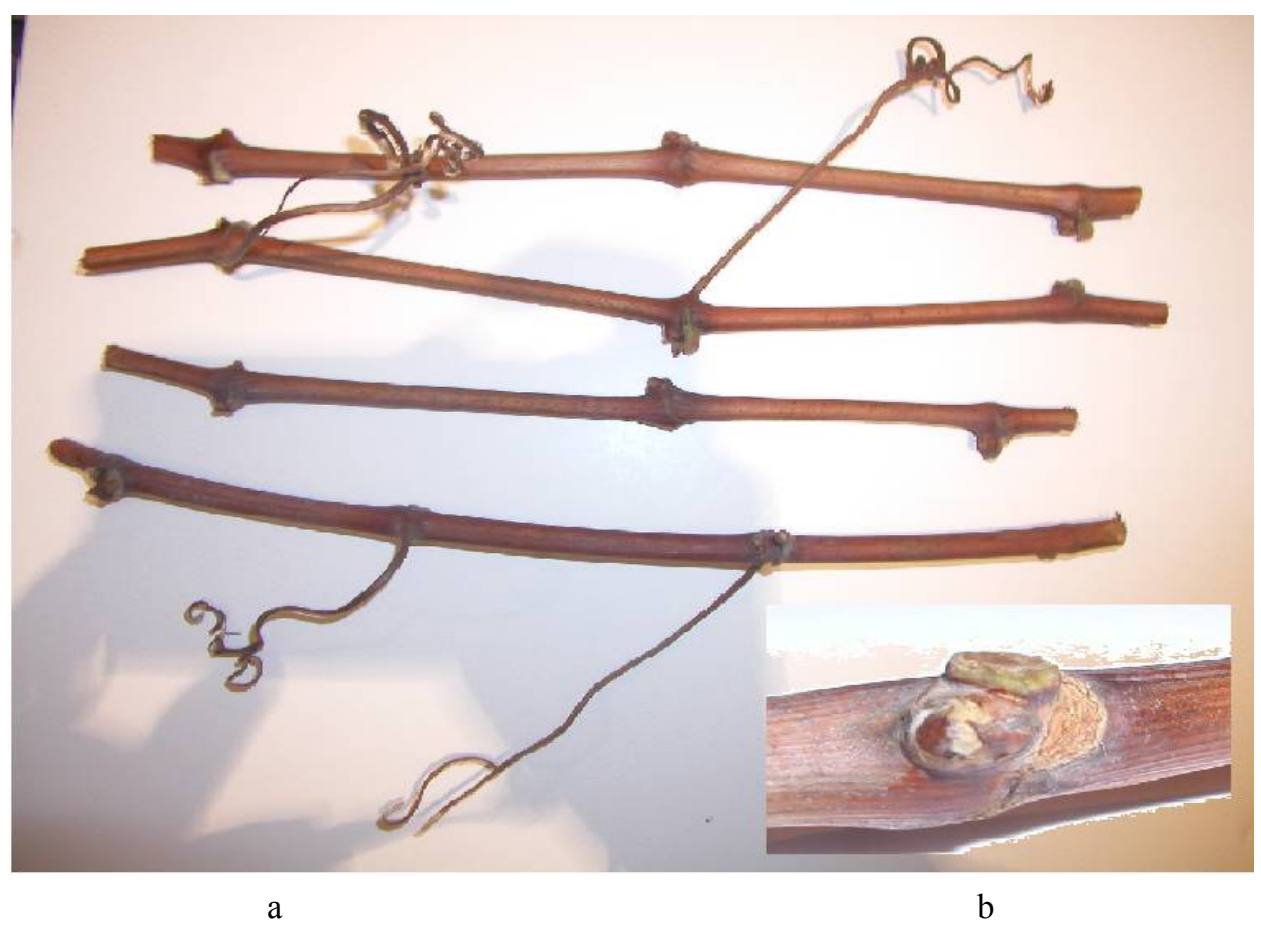

Figure 4. (a) Woodened canes and (b) winter bud of the vine variety Bacouri 